\title{
CHALLENGES OF WEB-BASED PARTICIPATORY LEARNING
}

\author{
Gilberto Marzano \\ Rezekne Academy of Technologies, Latvia \\ Luis Ochoa-Siguencia \\ The Jerzy Kukuczka Academy of Physical Education in Katowice - Poland
}

\begin{abstract}
In the last decade, the spread of the Internet has increased the importance of informal learning, since any sort of knowledge, both popular and scientific, can be found on the Internet in multifarious forms, e.g. online newspapers, books and e-books, scientific journals, blogs, forums, images, videos, etc.

This paper analyses some challenges of Web-based learning, and briefly reports on an experience of computer-supported collaborative learning that is based on a social learning approach.
\end{abstract}

Keywords: adult learning, computer-supported collaborative learning, online learning, participatory learning, social learning.

\section{Is learning via the Internet our new future?}

The internet is pervading every dimension of our contemporary society, including that of education. Distance learning programs and online courses are mushrooming, thanks to new education tools and cloud computing solutions. Online courses are spreading everywhere. Experts are persuaded that market demand will also push universities to quickly expand their current offer of online courses. In fact, nowadays, higher education institutions need to address the problem of preparing students for today's world of work, which is continually changing, and which requires the continuous resetting of knowledge and skills. Higher education institutions should integrate their traditional curricula with continuing professional development (CPD) programs, and accept that they must compete with other for-profit and non-profit subjects in the provision of educational programs and credentials, as well as in the tracking and documentation of professional skills, knowledge, and experience (Anderson, Boyles, \& Rainie, 2012). Online learning seems the only logical solution that satisfies the demands on modern education for an approach that is flexible, professional, and economically sustainable. 
There are, however, also those who don't share this enthusiasm for online education.

Their major criticisms revolve around two crucial aspects, namely content and effectiveness. How can one identify credible and reliable content on the internet? An emblematic case is that of Wikipedia, the popular open encyclopaedia that provides Internet users with a vast quantity of information. In fact, Wikipedia's articles are not always of high quality. Many of them are not exhaustive, or even contain information and data that is incorrect. Articles are usually anonymous, as very few authors use their real names, and, undoubtedly, this prevents the credibility of sources from being properly evaluated.

The criticism concerning effectiveness is related to the specific features of the online educational environment. It has been argued that taking classes on the internet is neither practical nor effective. For example, the interaction between teachers and students cannot be the same as it is in a traditional classroom, teachers cannot adapt their teaching style to the learning needs of students, and so on (Chan, 2003; Cowan, J. 2006). Accordingly, there are those who claim that online learning can never replace the face-to-face learning process.

Our opinion is quite different. Two main factors impact on the effectiveness of education processes (including Web-based learning): the educational purpose, and the educational context that includes the teacher excellence (Hatcher, Henson, \& LaRosa, 2013).

Accordingly, we are persuaded that the Internet can represent an important source of supplemental information, but it cannot be used for all types of learner, in all contexts, and always the same way.

This article reports on an experience that seems to support this opinion.

The aim of our article is to contribute to the current debate on the use of the internet in non-formal and informal learning sharing some reflections matured on the field.

It briefly presents an experience of social learning and computer-supported collaborative learning, which took place within a more complex experiment into online participatory learning with low-qualified adult learners.

From this experience, we derived some suggestions useful in the development of our experiment.

Before illustrating this example, it is useful to highlight a few concepts that form the theoretical background of our experience.

\section{Social learning}

It is universally accepted that the internet makes education accessible to all, since any kind of knowledge is available on the Web. For this reason, many organisations are experimenting with the use of social media within the 
workplace. Virtual communities are often created to provide information and support workers within an organisation or an institution. Furthermore, Big Data and data mining technologies are creating new learning needs aimed at effectively exploiting the mass of information available on the Web (Witten, Frank, Hall, \& Pal, 2016).

Recently, several researchers have started to investigate the non-formal and informal learning processes that take place on the Web, and the new term, social learning, was coined to designate this modality of learning (Baldwin, 2016).

In the literature, social learning is considered as a part of informal learning. For this reason, it is helpful to highlight some basic principles of informal learning.

The definition of informal learning is commonly introduced in terms of a contrast with formal learning (Marsick \& Watkins, 2001). In fact, in many respects, these two forms of learning are complementary.

Three basic types of informal learning have been identified:

- Self-directed learning that is intentional and conscious; it refers to learning programmes undertaken by individuals or groups without the assistance of teachers, instructors, or facilitators.

- Incidental learning that is not intentional but conscious; it occurs when we learn without any intention of learning, e.g. by direct experience.

- Socialisation that is not intentional and conscious; it refers to attitudes, beliefs, behaviours, and skills acquired in everyday life, often through imitation.

The main distinctiveness of informal learning is that it doesn't necessarily take place in a classroom, and learners are not always aware that they are involved in a learning process. Table 1 shows the most evident differences between formal and informal learning.

Table 1 The main differences between formal and informal learning

\begin{tabular}{|l|l|l|}
\hline & Formal learning & Informal learning \\
\hline Pedagogical approach & Teacher-centred & Learner centred \\
\hline Interaction & With the teacher & Interpersonal \\
\hline Location & Classroom & $\begin{array}{l}\text { Workplace, home, } \\
\text { community, etc. }\end{array}$ \\
\hline Process & Highly structured & Not structured \\
\hline Consciousness & Always & Not necessarily \\
\hline Modality & Explicit & By experience \\
\hline Knowledge & Vertical & Horizontal \\
\hline Paradigm & Acquisitional & Propositional \\
\hline Assessment and accreditation & Defined & Through progress \\
\hline
\end{tabular}


Simply put, informal learning doesn't foresee authorised curricula, and occurs outside the channels of formal and non-formal education. This explains the choice of expression informal learning rather than informal education.

In our opinion, considering social learning only as a part of informal learning is an evident reduction of the social learning scope. It appears, de facto, as a specific learning modality since it can be included in overall learning activities, especially in non-formal training programmes. For instance, trainings can include self-directed learning activities carried out on the Web. Sharing information and knowledge among peers by means of Web-based interactions is a usual practice (see forum discussions for the use of words or to solve computer problems. If you don't know how do something, for example how to open a file with the extension ".rar", you can search on the Web and find the software to download and manage this type of compressed file. Moreover, there are a huge variety of tools and sites available on the Web that support learning processes allowing collaborative technologies (groupware applications, webinars, online conferences, etc.) and which provide a wide range of peer-to-peer learning opportunities.

As a consequence of the digital revolution and the resulting instability of employment, integrative and flexible forms of education are in great demand. It is not the case that, in this decade, validation of non-formal and informal learning has suddenly become a topical issue and a priority for national and European vocational education and training (VET) policies.

Nowadays, social learning represents both an opportunity and a challenge for the training profession (Bowers \& Kumar, 2017). Benefits essentially concern the integration of formal curricula with just-in-time knowledge. Challenges concern how effectively it manages informal contents and the risks hidden in social media.

\section{An experience of computer-supported collaborative learning}

In the following paragraphs, we will illustrate and comment on an experience of computer-supported collaborative learning (CSCL) that took place within an EU two-year project, EScALADE, which focuses on adult participatory learning. This project involves five partners (from Italy, Latvia, Poland, Spain, and Greece), and foresees the experimentation of an online participatory learning approach on a target group formed of adults (55 years old). The EScALADE project aims to investigate to what extent, and in what ways, an online environment can affect adult learning. In fact, the main project goal is to study the advantages of, and barriers to, online non-formal and informal adult education.

For this purpose, an experimental training course was designed that focuses on some digital basic topics: Web searching, e-mailing, messaging, and word 
processing. The training course foresees both e-learning activities and participatory interactions among students, supported by facilitators.

EScALADE has been organised in three phases:

- $\quad$ Phase 1 , literature analysis and needs analysis, to define the project theoretical background and operative context;

- Phase 2, experiment design, training course implementation, and education of trainers;

- $\quad$ Phase 3, training course to be run in each of the countries participating in the project, analysis of results, and evaluation.

As of this time, phase 2 has been completed. Partners are ready to start with an experimental training course that will involve 20 adults and 2 facilitators. PBworks has been used to create four learning modules in English (Figure 1). Each partner has translated these modules into their respective native language, namely Italian, Latvian, Polish, Spanish, and Greek.

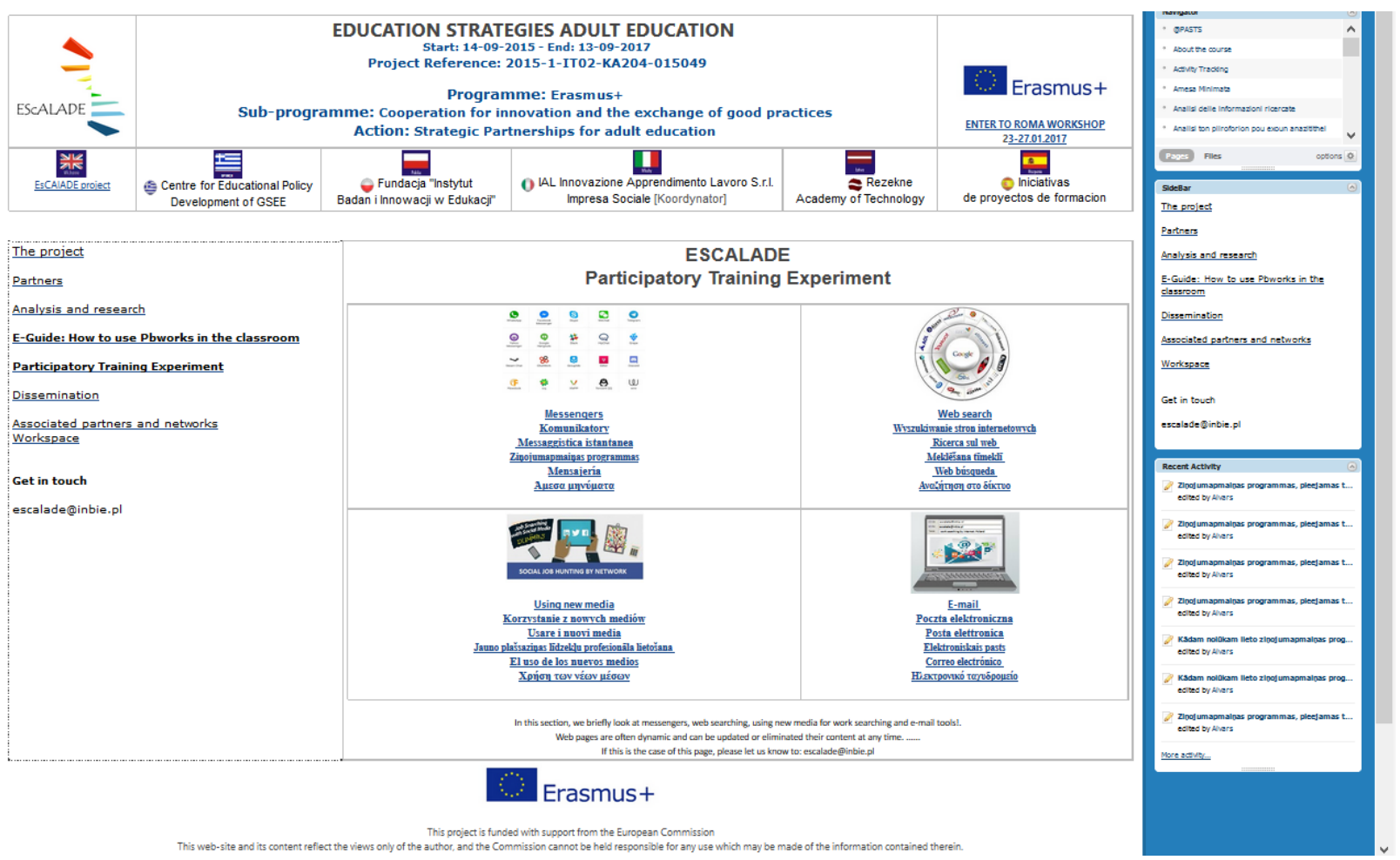

Figure 1 The EScALADE project PBworks page

Note that, as soon as we started to implement the English version of the training course, we immediately understood that some content should be customised and adapted to the local contexts of the project participating countries, e.g. selecting local Web sites and choosing alternative online resources. In fact, some different needs emerged owing to different local situations, e.g. different labour market situations, presence or absence of immigrants, and so on. In 
particular, some case studies and exercises needed to be re-formulated and recontextualised.

Furthermore, we sought to manage some factors related to the different local motivation of adult learners that emerged from the need analysis carried out in phase 1.

To harmonise the experiment and test it, a short training event of five days was organised involving trainers from the project participating countries. In this short training event, we used a CSCL approach (Andriessen, Baker, \& Suthers, 2013 ) with the aim of stimulating the learners' knowledge construction during the training process.

We were persuaded that a CSCL approach would facilitate the management of an inhomogeneous trainers' group formed by professionals and academics with different backgrounds and expectations.

However, we were aware that there are open questions relating to CSCL (Wilson \& Narayan, 2016), such as "Is CSCL context sensitive?" and "What are the appropriate means for supporting collaboration in an e-learning or distance learning environment?"

Finally, we considered that, in our training course, collaboration would assume two different forms: synchronous and asynchronous, and three different kinds of relations would take place:

$$
\begin{aligned}
& \text { Learners } \leftrightarrow \text { Learners } \\
& \text { Teachers } \leftrightarrow \text { Teachers } \\
& \text { Learners } \leftrightarrow \text { Teachers }
\end{aligned}
$$

\section{The EScALADE experience}

Nowadays, a wide range of tools and functions are available to facilitate and support a collaborative learning process. In the short training event, we decided to use three tools: SlideShare, PBworks, and CamStudio. We also devised some social learning activities to facilitate the teaching/learning process (Kwon, Liu, \& Johnson, 2014).

The trainees' group comprised 21 participants (Table 2).

Table 2 Composition of trainees group

\begin{tabular}{|c|c|c|c|}
\hline Country & Professional & Researcher & Other \\
\hline Italy & 4 & - & - \\
\hline Latvia & - & 4 & 1 \\
\hline Spain & 1 & - & 1 \\
\hline Poland & 4 & 1 & 1 \\
\hline Greek & 5 & - & - \\
\hline
\end{tabular}


The training course was run by three trainers/facilitators (from Italy, Latvia, and Poland) with experience in teaching professionals. The language used was English, although participants shared other languages (Spanish, Italian, French, and Russian) that they used to communicate in informal conversations.

The training room was equipped with computers, one computer for each participant, connected to the internet.

In the preparation phase, we received some criticism about the training course from academics. How could they participate in a training course where somebody would teach the same topics that they taught to students in their university? Nevertheless, we needed to give all participants the same notions that would be necessary for organising and managing the adult participatory learning experiment in their respective countries, irrespective of whether they were academics or not, so as not to disappoint any participant.

To achieve the project goal without creating problems among partners, we decided to organise the short training event following a participatory approach and including some social learning activities. We also decided to divide participants into 4 groups, each group formed of people from different countries in order to mitigate fussy interpretations and misunderstandings.

We started our training by submitting a test consisting of ten questions concerning SladeShare and PBworks. This test had the aim of giving participants the opportunity to self-evaluate their existing knowledge on the above products.

Then, we introduced SlideShare, underlining how a collaborative approach takes place and how SlideShare can support it. Many examples were presented highlighting the importance of the context, e.g. demonstrating how a very good presentation in a face-to-face context was not effective in an e-learning environment, and vice versa. Participants were involved in discussions about the integration of the various software tools in order to create effective online learning modules. YouTube videos were used to present basic concepts, choosing the most accredited references. The use of external materials and the involvement in a free discussion very quickly created a chatty atmosphere among participants (Roseth, Akcaoglu, \& Zellner, 2013).

Our goal was to put participants at ease, and at the same time to verify the effectiveness of using materials taken from the Web. We anticipated that either the direct involvement of learners in technical activities, such as searching the Web and using freeware software, or the opportunity to express their opinions through wiki would contribute to the success of the training (Zheng, Niiya, \& Warschauer, 2015).

At the beginning, participants were sitting grouped by country, preferring to stay close to their colleagues. However, the discussion prompted by facilitators created interactions between the different groups. Facilitators used the wellknown trick of asking if somebody was able to answer a particular question and 
inviting those who responded affirmatively to provide an explanation. Then, facilitators asked participants to add other useful information.

After about an hour, it was possible to gather several points on which participants agreed. The principal points that were noted were as follows:

- No subject is important in itself, but its importance depends on the context;

- A good presentation in an academic context cannot have the same effect in a context of adult learners;

- $\quad$ Terms such as low-skilled and unskilled assumed different meanings among participants;

- Integrating different tools can enhance the learning results;

- Different tools can facilitate the learning goals;

- To achieve e-learning goals it can be useful to co-operate;

- Colleagues' experience and knowledge is a precious resource;

- Nobody should be afraid of making mistakes;

- Resources available on the Web can be useful but need to be used carefully.

The above elements were observed by two facilitators according to a grid defined at the time the training course was designed.

From that point, any problem could be solved. The creation of working groups became easy. Facilitators invited participants to designate four leaders and form four groups that would work independently to implement a 15 minutes presentation using SlideShare, PBworks, and CamStudio. Groups were allowed to integrate these tools with others if they considered them necessary or advantageous. One leader was self-proposed, a second was chosen by colleagues, and two were gently co-opted.

The groups worked together, either occupying a physical classroom, or remotely by using PCs and exchanging e-mails and messages.

By means of another ruse, facilitators forced groups to work remotely, outside the classroom. One day, they suspended the course from 14:00 to 17:00 inviting participants to spend this time in cultural activities (a tourist tour), but participants were required to finish a task they had started by communicating at a distance. The work was to be presented by each group the following morning.

\section{Conclusion}

Although, at the moment, we have not yet completed the analysis of qualitative data (facilitators' observations) and quantitative data (two tests and a questionnaire), we can state that, based on the learners' reactions, the participatory 
approach and the social learning activities contributed to the success of our brief training event.

Nevertheless, we can observe that an effective use of social learning cannot disregard the context and a careful design of learner engagement strategies.

Under many aspects, our learning experience confirmed that, in designing effective CSCL systems, the main issue is not to create new tools, but to assemble, integrate, and increase the usability of those tools already available.

From our experience, it emerged the importance of the context. In our case, both the group relationships and the capability of facilitators resulted to be relevant.

Accordingly, a question raised. How can we control the contextual factors in a completely online learning environment? Of course, we can easily control the online interactions, but in what measure will the real environment where the learning process takes place interfere with the learners' activity?

We decided to consider the weight of the real environment in the experiment with low-qualified adults. A questionnaire has been implemented and will be used during the experiment to analyze the correlation between the real environment and the learning results.

\section{References}

Anderson, J. Q., Boyles, J. L., \& Rainie, L. (2012). The Future Impact of the Internet on Higher Education: Experts Expect More Efficient Collaborative Environments and New Grading Schemes; They Worry about Massive Online Courses, the Shift Away from On-Campus Life. Pew Internet \& American Life Project. http://files.eric.ed.gov/ fulltext/ED534048.pdf; last accessed 25.01.2017.

Andriessen, J., Baker, M., \& Suthers, D. (Eds.). (2013). Arguing to learn: Confronting cognitions in computer-supported collaborative learning environments (Vol. 1). Springer Science \& Business Media.

Chan, E. (2003). Exploring the roles of teachers in computer mediated communication activities. In World Conference on Educational Multimedia, Hypermedia and Telecommunications 2003.

Coffield, F. (2000). The necessity of informal learning (Vol. 4). Policy press.

Cowan, J. (2006). Introduction. In J. O'Donoghue, Technology supported learning and teaching - A staff perspective. London: Idea Group. 1-13.

Baldwin, M. (2016). Social work, critical reflection and the learning organization. Routledge. Bowers, J., \& Kumar, P. (2017). Students' perceptions of teaching and social presence: A comparative analysis of face-to-face and online learning environments. In Blended Learning: Concepts, Methodologies, Tools, and Applications (pp. 1532-1550). IGI Global.

Hatcher, M., Henson, J., \& LaRosa, P. (2013). Determinants of success in an online management information systems course: The significance of grade point average as a performance predictor. International Journal of Business Strategy, 13 (4), 129-132. 
Kwon, K., Liu, Y. H., \& Johnson, L. P. (2014). Group regulation and social-emotional interactions observed in computer supported collaborative learning: Comparison between good vs. poor collaborators. Computers \& Education, 78, pp. 185-200.

Marsick, V. J., \& Watkins, K. E. (2001). Informal and incidental learning. New directions for adult and continuing education, 2001 (89), pp. 25-34.

Roseth, C., Akcaoglu, M., \& Zellner, A. (2013). Blending synchronous face-to-face and computer-supported cooperative learning in a hybrid doctoral seminar. TechTrends, 57 (3), pp. 54-59.

Wilson, K., \& Narayan, A. (2016). Relationships among individual task self-efficacy, selfregulated learning strategy use and academic performance in a computer-supported collaborative learning environment. Educational Psychology, 36 (2), pp. 236-253.

Witten, I. H., Frank, E., Hall, M. A., \& Pal, C. J. (2016). Data Mining: Practical machine learning tools and techniques. Morgan Kaufmann.

Zheng, B., Niiya, M., \& Warschauer, M. (2015). Wikis and collaborative learning in higher education. Technology, Pedagogy and Education, 24 (3), pp. 357-374. 